\title{
Circulating miRNAs as a marker of metastatic disease Paper prognostic factor in metastatic breast cancer
}

\author{
Chara Papadaki ${ }^{1}$, Giannis Stoupis ${ }^{2}$, Leuteris Tsalikis $^{1}$, Alexia Monastirioti ${ }^{1}$, Maria \\ Papadaki $^{1}$, Neofytos Maliotis ${ }^{1}$, Michalis Stratigos ${ }^{2}$, Georgios Mastrostamatis ${ }^{1}$, \\ Dimitrios Mavroudis ${ }^{1,2}$ and Sofia Agelaki ${ }^{1,2}$ \\ ${ }^{1}$ Laboratory of Translational Oncology, School of Medicine, University of Crete, Heraklion, Greece \\ ${ }^{2}$ Department of Medical Oncology, University General Hospital, Heraklion, Crete, Greece \\ Correspondence to: Sofia Agelaki, email: agelakisofia@gmail.com \\ Keywords: circulating miRNAs; breast cancer; metastasis; prognosis \\ Abbreviations: MBC: metastatic breast cancer; PFS: progression free survival; OS: overall survival \\ Received: November 29, $2018 \quad$ Accepted: January 12, $2019 \quad$ Published: January 29, 2019 \\ Copyright: Papadaki et al. This is an open-access article distributed under the terms of the Creative Commons Attribution License \\ 3.0 (CC BY 3.0), which permits unrestricted use, distribution, and reproduction in any medium, provided the original author and \\ source are credited.
}

\section{ABSTRACT}

Background: Circulating miRNAs (miRs) are increasingly recognized as potential biomarkers in cancer. We aimed to evaluate the differential expression of miR-23b and miR-190 which are involved in tumor dormancy, miR-21 involved in metastasis and $\mathbf{m i R}-200 \mathrm{~b}$ and $\mathrm{miR}-200 \mathrm{c}$ involved in epithelial-mesenchymal transition (EMT) and metastasis, in the plasma of patients with early and metastatic breast cancer (MBC). We also aimed to identify associations of the expression levels with patient and disease characteristics and outcomes in metastatic patients treated with firstline chemotherapy.

Results: $\operatorname{miR}-21(p<0.001), \operatorname{miR}-23 b(p=0.033), \operatorname{miR}-200 b(p<0.001)$ and miR-200c $(p<0.001)$ expression was higher in metastatic compared to early breast cancer. ROC curve analysis showed that miR-21 (AUC $=0.722 ; p<0.001$ ) and miR200b (AUC $=0.720 ; p<0.001$ ) distinguished with high accuracy among the two disease states, whereas the combination of miR-21, miR-190, miR-200b and miR200c, further improved accuracy (AUC $=0.797 ; p<0.001$ ). High miR-200b expression independently predicted for shorter OS $(p=0.026)$ in MBC. High expression of both miR23b and miR-190 emerged as a strong independent factor associated with shorter PFS $(p=0.001)$ in de novo metastatic patients and high miR-200b independently predicted for decreased OS in the HER2-negative subgroup $(p=0.007)$.

Materials and Methods: Blood samples were obtained from patients with early ( $n=133)$ and MBC $(n=110)$ before adjuvant or first-line chemotherapy, respectively. Plasma miRNA expression levels were assessed by RT-qPCR and were classified as high or low according to the median values.

Conclusions: Our results are in support of the concept that circulating miRNAs represent a tool with significant diagnostic and prognostic implications in breast cancer.

\section{INTRODUCTION}

Despite advances in diagnosis and treatment, breast cancer remains the leading cause of cancer-related death in women worldwide [1]. Twenty to $30 \%$ of patients with early disease develop disease recurrence which remains the main cause of morbidity and mortality for these patients [2]. Unfortunately, the prognosis of patients with advanced or recurrent breast cancer has only modestly improved during the last three decades [3] with median survival and 5 -year survival of approximately 3 years and $25 \%$, respectively [4]. The outcome of metastatic 
patients depends on clinicopathologic factors such as hormone receptor (HR) and human epidermal growth factor receptor 2 (HER2) status, performance status, age at initial diagnosis and site and number of distant metastases $[5,6]$. However, breast cancer is extremely heterogeneous with diverse clinical outcomes that cannot be captured by current prognostic factors [7]. Novel prognostic markers are needed to better stratify metastatic patients and to provide meaningful prognostic estimates [7, 8].

MicroRNAs (miRNAs) are small (22 nt) noncoding RNAs involved in the epigenetic regulation of mRNA [9]. miRNAs are dysregulated in human cancers [10] and operate as oncogenes or tumor suppressor genes, depending on the context [11]. Deregulated miRNA expression is involved in different steps of tumor progression including tumor dormancy, EMT, proliferation and metastasis [12, 13]. The potential of miRNAs as biomarkers in cancer has been increasingly recognized [14]. Indeed, recent studies reveal that miRNA expression in tumor samples has been associated with tumor aggressiveness, response to treatment and patient outcomes in various tumor types including breast cancer $[12,15-17]$. Unique miRNA profiles evaluated in the serum or plasma have a role in the early detection of cancer $[17,18]$, in the discrimination between metastatic and non-metastatic disease states $[19,20]$ and in the prediction of clinical outcome in patients with cancer $[21,22]$. In addition, in a recent report, a serum miRNA signature predicted response in patients with HER2positive disease receiving the targeted therapy trastuzumab [23].

In a recent study we showed that the expression of miR-21 (related to metastasis), mir-23b and miR-190 (related to tumor dormancy) and $\mathrm{miR}-200 \mathrm{~b} / \mathrm{c}$ (related to EMT), evaluated in the plasma of patients with early breast cancer before the initiation of adjuvant chemotherapy were differentially expressed among patients who subsequently experienced disease recurrence compared to those who remained disease-free during follow-up [24]. Interestingly, miRNAs could predict for disease recurrence years before the clinical detection of metastases [24].

Based on the above findings we sought to evaluate whether the aforementioned miRNAs could also discriminate among patients with early and MBC and whether they could be used for the refinement of prognosis in patients with metastatic disease.

\section{RESULTS}

\section{Differential expression of miRNAs and their predictive capability in distinguishing early from MBC}

We compared the expression of miRNAs in patients with early $(n=133)$ and metastatic $(n=70)$ breast cancer. The characteristics of patients with metastatic disease are presented in Table 1. Median age was 63 years (range, 30-84), 45 (64\%) had de novo metastatic disease and 51 (73\%) were HER2-negative.

The Mann-Whitney tests for miRNA expression revealed that the expression levels of miR-21 $(p<0.001)$, miR-23b $(p=0.033), \operatorname{miR}-200 \mathrm{~b}(p<0.001)$ and miR-200c $(p<0.001)$ were higher in metastatic compared to patients with early disease (Figure 1).

We next evaluated the predictive capability of plasma miRNAs in distinguishing between early and metastatic patients. Binary logistic regression incorporating various combinations of miRNAs was used and ROC curves were constructed to determine the specificity and sensitivity of miRNA expression (Figure 2 and Table 2). ROC curve analysis showed that among the investigated miRNAs, miR-21 and miR-200b expression had the highest performance with an AUC of 0.722 [sensitivity of $51.4 \%$ and specificity of $83.3 \%(p<0.001$; $95 \%$ CI $0.648-0.796)$ ] and AUC of 0.720 [sensitivity of $60 \%$ and specificity of $75.8 \%(p<0.001 ; 95 \%$ CI: 0.644 $0.796)$ ] (Figure 2A-2E). By assessing combinations of miRNAs, binary logistic regression analysis demonstrated that the panel of miR-21, miR-190, miR-200b and miR200c had the highest predictive accuracy. Specifically, the combined ROC curve of the panel had an AUC of 0.797 with sensitivity of $72.7 \%$ and specificity of $75 \%(p<$ 0.001; 93\% CI: 0.727-0.866) (Figure 2F).

\section{miRNA expression and statistical correlations in MBC patients}

A strong correlation was observed between the expression of miR-200b and miR-200c (Spearman's Rho: $0.763 ; p<0.001)$. Moreover, a strong correlation was observed between the expression of miR-21 and miR-200c (Spearman's Rho: 0.605; $p<0.001$ ) and between miR21 and miR-200b (Spearman's Rho: 0.554; $p<0.001$ ). A weaker but still significant correlation was revealed between miR-21 and miR-23b (Spearman's Rho: 0.309; $p=0.009$ ), between miR-23b and miR-190 (Spearman's Rho: $0.302 ; p=0.014$ ) and between miR-23b and miR200c (Spearman's Rho: 275; $p=0.021$ ) as well (Table 3).

Higher miR-21 and miR-200b expression was observed in patients with pre-menopausal compared to patients with post-menopausal status (chi-squared test: $69 \%$ vs $31 \% ; p=0.015$ and 67 vs $33 ; p=0.013$, respectively). Patients with low expression of miR-190 had increased incidence of bone metastases as compared to those with high expression (chi-squared test: $70 \%$ vs $30 \% ; p=0.019)$. We did not observe any differences in miRNA expression among patients presenting with de novo metastatic $(n=45)$ and those with recurrent disease $(n=25$; Mann-Whitney tests, $p>0.05)$. Moreover, no differences in miRNA expression were revealed among HER-2 negative $(n=51)$ and HER-2 positive $(n=19)$ patients (Mann-Whitney tests, $p>0.05$ ). 
Table 1: Characteristics of patients with $\mathrm{MBC}$

\begin{tabular}{|c|c|c|c|c|c|c|}
\hline \multirow{2}{*}{ Characteristic } & \multicolumn{2}{|c|}{ All patients } & \multicolumn{2}{|c|}{ de novo metastatic } & \multicolumn{2}{|c|}{ HER2-negative } \\
\hline & $N$ & $\%$ & $N$ & $\%$ & No. & $\%$ \\
\hline Patients enrolled & 70 & 100 & 45 & 64 & 51 & 73 \\
\hline \multicolumn{7}{|l|}{ Age (years) } \\
\hline Median (range) & \multicolumn{2}{|c|}{$63(30-84)$} & \multicolumn{2}{|c|}{$60(31-82)$} & \multicolumn{2}{|c|}{$63(30-84)$} \\
\hline \multicolumn{7}{|l|}{ Menopausal status } \\
\hline Pre & 38 & 54 & 25 & 56 & 27 & 53 \\
\hline Post & 32 & 46 & 20 & 44 & 24 & 47 \\
\hline \multicolumn{7}{|l|}{ Performance status } \\
\hline $0-1$ & 58 & 83 & 33 & 73 & 43 & 84 \\
\hline 2 & 12 & 17 & 12 & 27 & 8 & 16 \\
\hline \multicolumn{7}{|l|}{ Disease status at diagnosis } \\
\hline Recurrent & 25 & 36 & & & 22 & 43 \\
\hline de novo metastatic & 45 & 64 & & & 29 & 57 \\
\hline \multicolumn{7}{|l|}{ Histological Grade } \\
\hline $\mathrm{I} / \mathrm{II}$ & 32 & 46 & 24 & 53 & 23 & 45 \\
\hline III & 26 & 37 & 13 & 29 & 17 & 33 \\
\hline Unknown & 12 & 17 & 8 & 18 & 11 & 22 \\
\hline \multicolumn{7}{|l|}{ ER status } \\
\hline Positive & 53 & 76 & 35 & 78 & 41 & 80 \\
\hline Negative & 15 & 21 & 10 & 22 & 8 & 16 \\
\hline Unknown & 2 & 3 & & & 2 & 4 \\
\hline \multicolumn{7}{|l|}{ PR status } \\
\hline Positive & 48 & 68 & 29 & 64 & 36 & 70 \\
\hline Negative & 20 & 29 & 16 & 36 & 13 & 26 \\
\hline Unknown & 2 & 3 & & & 2 & 4 \\
\hline \multicolumn{7}{|l|}{ HER2 status } \\
\hline Positive & 19 & 27 & 16 & 36 & & \\
\hline Negative & 51 & 73 & 29 & 64 & & \\
\hline \multicolumn{7}{|l|}{ First line chemotherapy } \\
\hline Taxane-based & 45 & 64 & 28 & 62 & 33 & 65 \\
\hline Taxanes + Anthracyclines & 13 & 19 & 8 & 18 & 13 & 25 \\
\hline Anthracycline-based & 3 & 4 & 2 & 4 & 3 & 6 \\
\hline Others & 9 & 13 & 7 & 16 & 2 & 4 \\
\hline \multicolumn{7}{|l|}{ Response to treatment } \\
\hline $\mathrm{CR}+\mathrm{PR}$ & 31 & 44 & 20 & 44 & 23 & 45 \\
\hline $\mathrm{SD}+\mathrm{PD}$ & 39 & 56 & 25 & 56 & 28 & 55 \\
\hline \multicolumn{7}{|l|}{ Visceral metastases } \\
\hline Yes & 47 & 67 & 32 & 71 & 31 & 61 \\
\hline No & 19 & 27 & 11 & 24 & 18 & 35 \\
\hline Unknown & 4 & 6 & 2 & 4 & 2 & 4 \\
\hline
\end{tabular}




\section{Non visceral metastases}

\begin{tabular}{lcccccc} 
Yes & 56 & 80 & 39 & 87 & 41 & 80 \\
No & 10 & 14 & 4 & 9 & 8 & 16 \\
Unknown & 4 & 6 & 2 & 4 & 2 & 4 \\
\hline
\end{tabular}

ER, estrogen receptor; PR, progesterone receptor; HER2, human epidermal growth factor receptor 2; CR, complete response; PR, partial response; $\mathrm{SD}$, stable disease; $\mathrm{PD}$, progressive disease.

No other significant correlations were observed between miRNA expression and clinicopathological parameters or the type of first line chemotherapy regimens administered.

\section{miRNA expression and clinical outcome in $\mathrm{MBC}$}

The median PFS and OS for the whole group of patients were 11.47 months (95\% CI: 7.89-15.05) and 27.33 months (95\% CI: 20.97-33.69), respectively. The type of first line chemotherapy was not associated with patients' outcomes. We used the median expression levels for each miRNA to classify patients into high or low expression groups. Kaplan Meier survival curves demonstrated that patients with high miR-21, miR-23b or miR-190 had significantly shorter PFS compared to those with low expression (10.8 vs 15.1 months; $p=0.044$, 10.57 vs 19.60 months; $p=0.018$ and 8.3 vs 19.6 months; $p=0.033$, respectively) (Figure 3A-3C). Moreover, the combination of miR-23b and miR-190 high expression was associated with shorter PFS as compared to low expression (8.3 vs 17.87 months; $p=0.003$; Figure 3D). In addition, patients with high miR-200b had shorter OS compared to those with low expression (27.33 vs 30.87 months; $p=0.024$ (Figure 3E). No differences in either PFS or OS were observed according to the median expression values for the remaining miRNAs.

Cox univariate analysis revealed that premenopausal status and recurrent disease were associated with shorter PFS ( $p=0.017$ and $p=0.012$, respectively; Table 4), whereas recurrent disease was associated with shorter OS $(p=0.003)$. Regarding the expression of miRNAs, high miR-21, miR-23b or miR-190 and high expression of both miR-23b and miR-190 were associated with shorter PFS $(p=0.046, p=0.02, p=0.035$ and $p$ $=0.007$, respectively; Table 4 ), whereas high expression
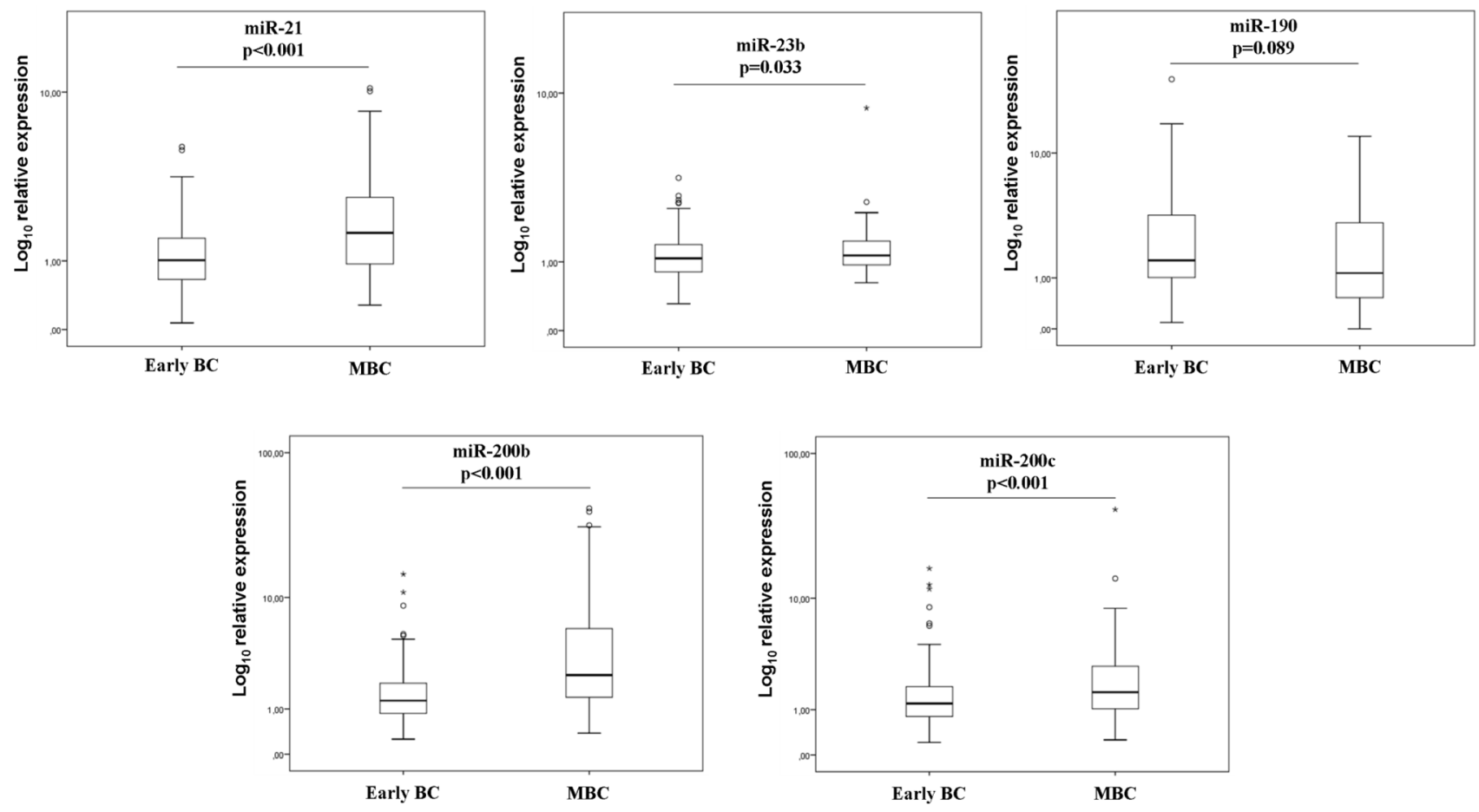

Figure 1: Relative expression levels of circulating miRNAs of early and metastatic patients. Expression levels of miR-21 (A), miR-23 (B), miR-190 (C), miR-200b (D) and miR-200c (E) were evaluated in the plasma by RT-qPCR and assessed by $2^{-\Delta \Delta C t}$ method. Statistically significant differences were determined using Mann-Whitney tests and the results were displayed on box plots. Horizontal line depicts median, whereas the length of the boxes is the interquartile range that represents values between the 75 th and 25 th percentiles of individual fold change expression values. Relative expression values on y-axis are plotted on a $\log _{10}$ scale. Circles represent outliers, whereas asterisks represent extreme outliers. $P$ values are shown. 
of miR-200b was associated with shorter OS ( $p=0.027$; Table 4). Multivariate analysis confirmed pre-menopausal status and both miR-23b/miR-190 high expression as independent predictors for shorter PFS ( $p=0.047$ and $p=0.009$, respectively; Table 4 ). In addition, disease recurrence and high expression of miR-200b were also independently associated with shorter OS $(p=0.003$ and 0.026, respectively; Table 4).

\section{miRNA expression and clinical outcome according to patient subgroups}

\section{Patients with de novo metastatic disease}

Patients' characteristics are shown in Table 1. Higher miR-21 expression was observed in pre-menopausal as compared to post-menopausal and in HER2-negative as compared to HER2-positive patients (chi-squared test: $74 \%$ vs $26 \% ; p=0.012$ and $78 \%$ vs $22 \% ; p=0.047$, respectively). Moreover, lower miR-190 expression was observed in patients with bone metastases as compared to patients without bone metastases (chi-squared test: $60 \%$ vs $40 \% ; p=0.008)$.
The median PFS and OS for the de novo metastatic subgroup was 16.8 months (95\% CI: 9.38-24.15) and 35.47 months (95\% CI: 24.92-46.02) respectively. Patients with miR-21, miR-23b or miR-190 high expression had significantly shorter PFS compared to patients with low expression (11.63 vs 20.97 months; $p=0.019,10.57$ vs 20.97; $p=0.008$, and 8.3 vs 20.97 months; $p=0.015$, respectively) (Figure 4A-4C). Furthermore, patients with both miR-23b and miR-190 high expression had shorter PFS (8.3 vs 20.8 months; $p=0.002$; Figure 4D). High miR-200b was significantly associated with worse OS (32.9 vs 54.1 months; $p=0.021$ ) compared to patients with low expression (Figure 4E).

In univariate analysis, pre-menopausal status and poor performance status were associated with significantly shorter PFS ( $p=0.016$ and $p=0.017$, respectively) and OS ( $p=0.025$ and $p=0.003$, respectively) (Table 5). Also, high expression of miR-21, miR-23b or miR-190 were significantly associated with shorter PFS ( $p=0.016, p=$ 0.017 and $p=0.028$, respectively). In addition, both miR23b and miR-190 high expression were also associated with shorter PFS ( $p=0.003$; Table 5). In multivariate
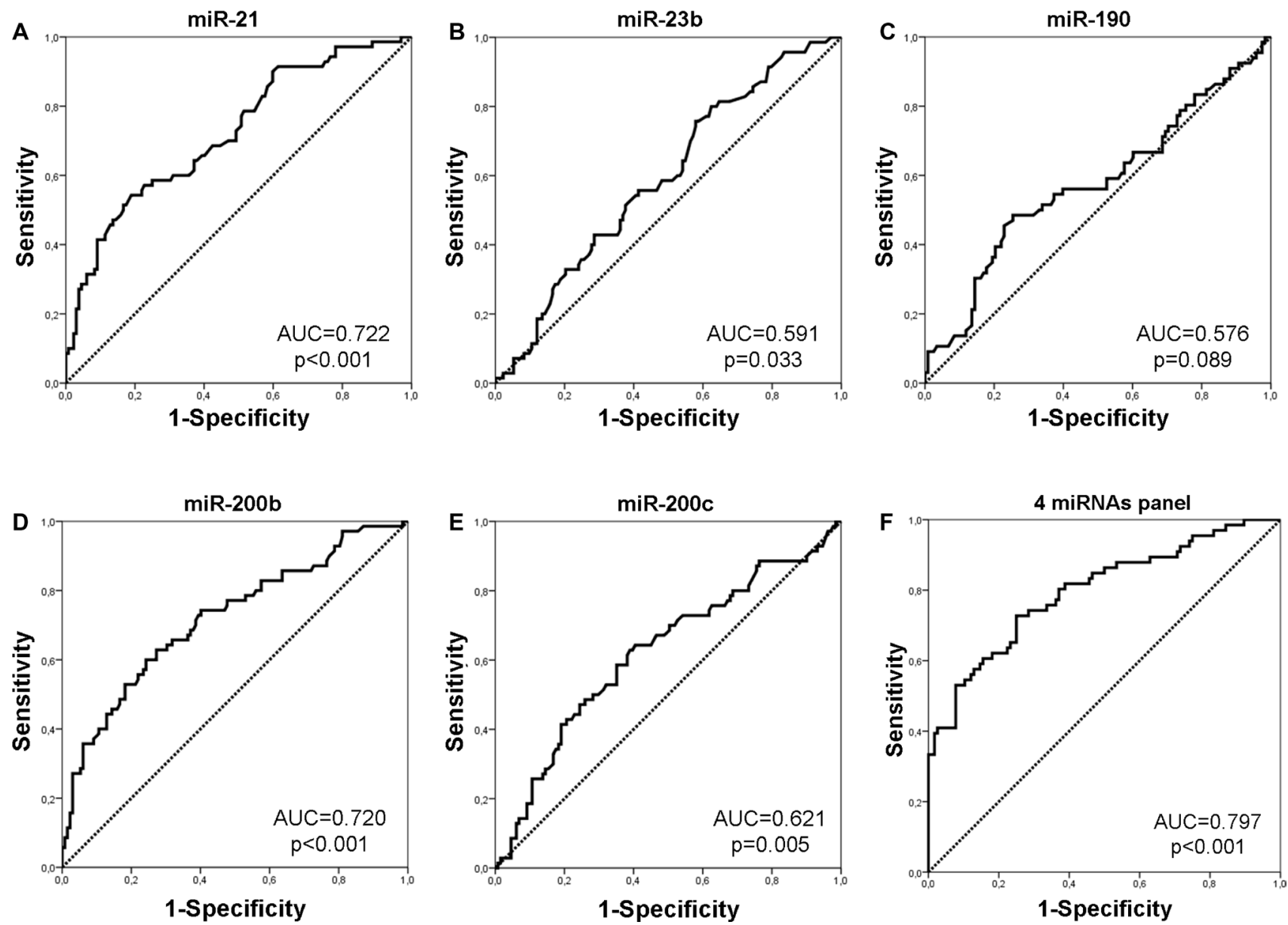

Figure 2: ROC curve analysis. Performance of plasma miR-21 (A), miR-23 (B), miR-190 (C), miR-200b (D) and miR-200c (E) and their combined expression $(\mathbf{F})$ to discriminate patients with early and those with MBC. AUC and $p$ values are shown. 
Table 2: Performance of miRNAs and their combinations to predict disease status in breast cancer

\begin{tabular}{lccccc}
\hline Potential predictors & $\begin{array}{c}\text { Cut-off } \\
\text { value }\end{array}$ & Sensitivity \% & Specificity \% & AUC (95\% CI) & $P$ \\
\hline miR-21 & 1.65 & 51.4 & 83.3 & $0.722(0.648-0.796)$ & $<0.001$ \\
miR-23b & 0.93 & 75.7 & 42.1 & $0.591(0.511-0.672)$ & 0.033 \\
miR-190 & 1.02 & 48.5 & 74.6 & $0.576(0.486-0.665)$ & 0.089 \\
miR-200b & 2.06 & 60.0 & 75.8 & $0.720(0.644-0.796)$ & $<0.001$ \\
miR-200c & 1.35 & 62.9 & 61.1 & $0.621(0.538-0.705)$ & 0.005 \\
4 miRNAs panel (miR-21, miR-190, miR- & & & & & \\
200b, miR-200c) & 0.31 & 72.7 & 75 & $0.797(0.727-0.866)$ & $<0.001$ \\
\hline
\end{tabular}

AUC, area under the receiver operating curve.

analysis, pre-menopausal status, poor performance status, and both miR-23b and miR-190 high expression were independent prognostic factors for decreased PFS $(p<$ $0.001, p=0.001$ and $p=0.001$, respectively), whereas only pre-menopausal status emerged as independent predictor for decreased OS ( $p<0.001$; Table 5).

\section{Her-2 negative patients}

Patients' characteristics are shown in Table 1. Higher miR-23b expression was observed in PR-positive as compared to PR- negative patients (chi-squared test:
$85 \%$ vs $15 \% ; p=0.041)$. Furthermore, patients with low miR-190 expression had increased risk of bone metastases as compared to patients with high expression.

The median PFS and OS were 12.57 months $(95 \%$ CI: 6.672-18.47) and 27.33 months (95\% CI: 19.1835.48 ), respectively in this subgroup of patients. Patients with both miR-21 and miR-23b high expression had significantly shorter PFS (10.57 vs 19.67 months; $p=$ 0.031 ) compared to patients with low expression (Figure 5A). Furthermore, patients with miR-200b high expression had shorter OS compared to patients with low expression (23.8 vs 42.7 months; $p=0.009$ ) (Figure 5B).
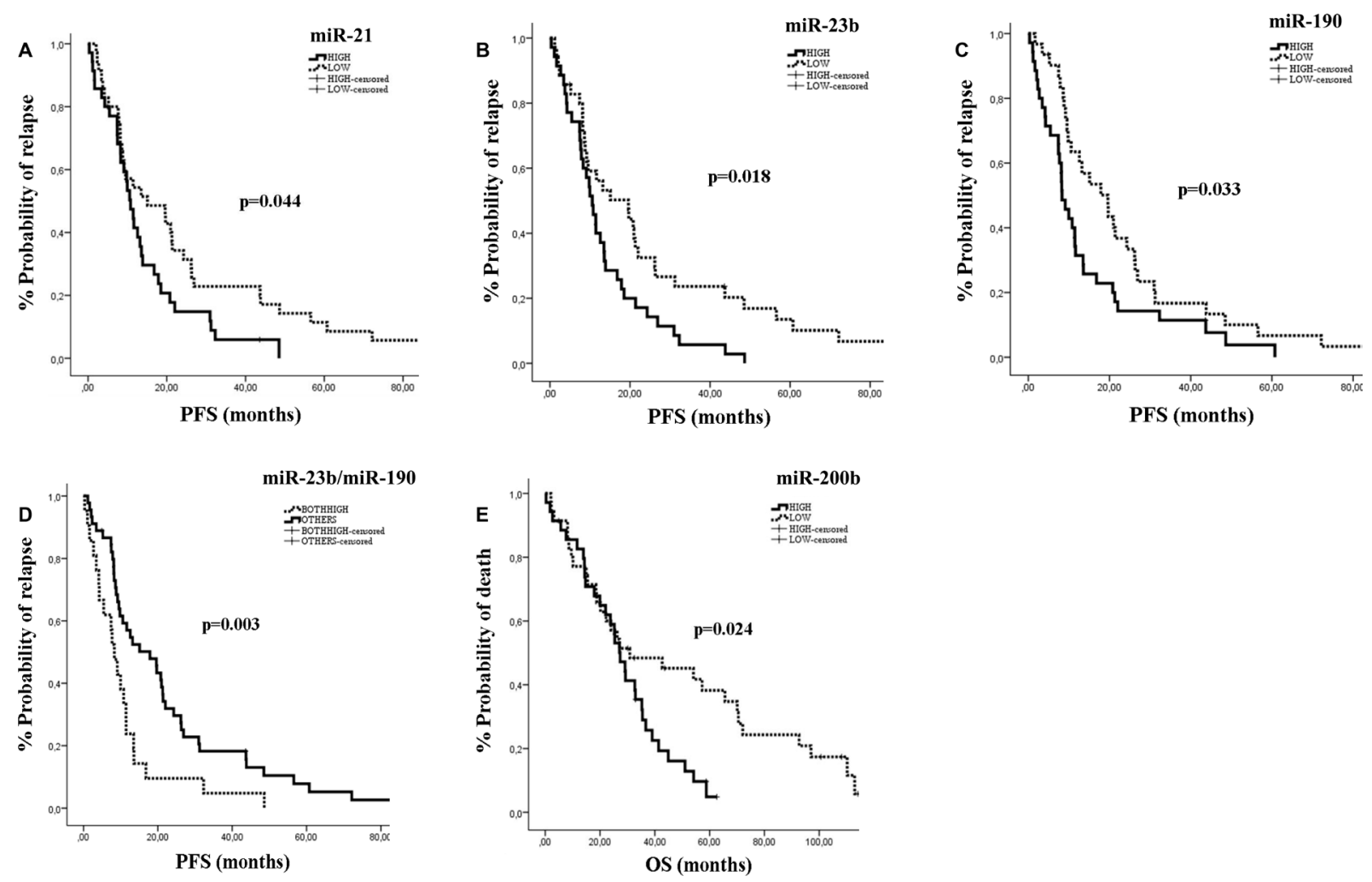

Figure 3: Kaplan-Meier analysis for PFS and OS according to the expression of circulating miRs in MBC patients. Progression free survival and overall survival in patients with high or low miR-21 (A), miR-23b (B), miR-190 (C), miR-23b/miR-190 (D) and miR-200b (E). Curves were compared using the log rank test. $P$ values are shown. 


\begin{tabular}{lccccc}
\hline & miR-21 & miR-23b & miR-190 & miR-200b & miR-200c \\
\hline miR-21 & 1.000 & & & & \\
miR-23b & $0.309^{* *}$ & 1.000 & & & \\
miR-190 & 0.136 & $0.302^{*}$ & 1.000 & & \\
miR-200b & $0.554^{* *}$ & 0.206 & 0.041 & 1.000 & 1.000 \\
miR-200c & $0.605^{* *}$ & $0.275^{*}$ & 0.056 & $0.763^{* *}$ & \\
\hline
\end{tabular}

${ }^{* *} p<0.01 ;{ }^{*} p<0.05$.

Cox univariate analysis revealed that recurrent breast cancer and high expression of both miR-21 and miR-23b were associated with shorter PFS ( $p=0.018$, and $p=0.034$, respectively) (Table 5). Moreover, recurrent disease and high expression of miR-200b and both miR2 1 and miR-23b high expression were associated with shorter OS ( $p=0.005, p=0.011$ and $p=0.038$, respectively) (Table 5). In multivariate analysis, recurrent disease was independently associated with worse PFS $(p=0.018)$ and worse OS ( $p=0.003)$, whereas, miR-200b high emerged as an independent prognostic factor for worse OS ( $p=$ 0.007) (Table 5).

\section{DISCUSSION}

$\mathrm{MBC}$ has a dismal prognosis and novel biomarkers indicative of the inherent biologic behaviour of the disease could improve patient prognostication. The identification of novel blood-based biomarkers with clinical application in breast cancer represents a challenge in translational cancer research. In the current study we report that the dormancy and metastasis-related miR-21, miR-23b, miR$200 \mathrm{~b}$ and miR-200c are differentially expressed among patients with early and $\mathrm{MBC}$ and that the combination of miR-21, miR-190, miR-200b and miR-200c was more informative in predicting early versus metastatic disease status. Furthermore, we show that the expression levels of circulating miRNAs are correlated with patient and disease characteristics and independently predict for clinical outcome in metastatic patients treated with firstline chemotherapy.

In our previous work, plasma expression levels of miR-21, miR-23b, miR-190 and miR-200b/c differed among patients with early breast cancer who subsequently
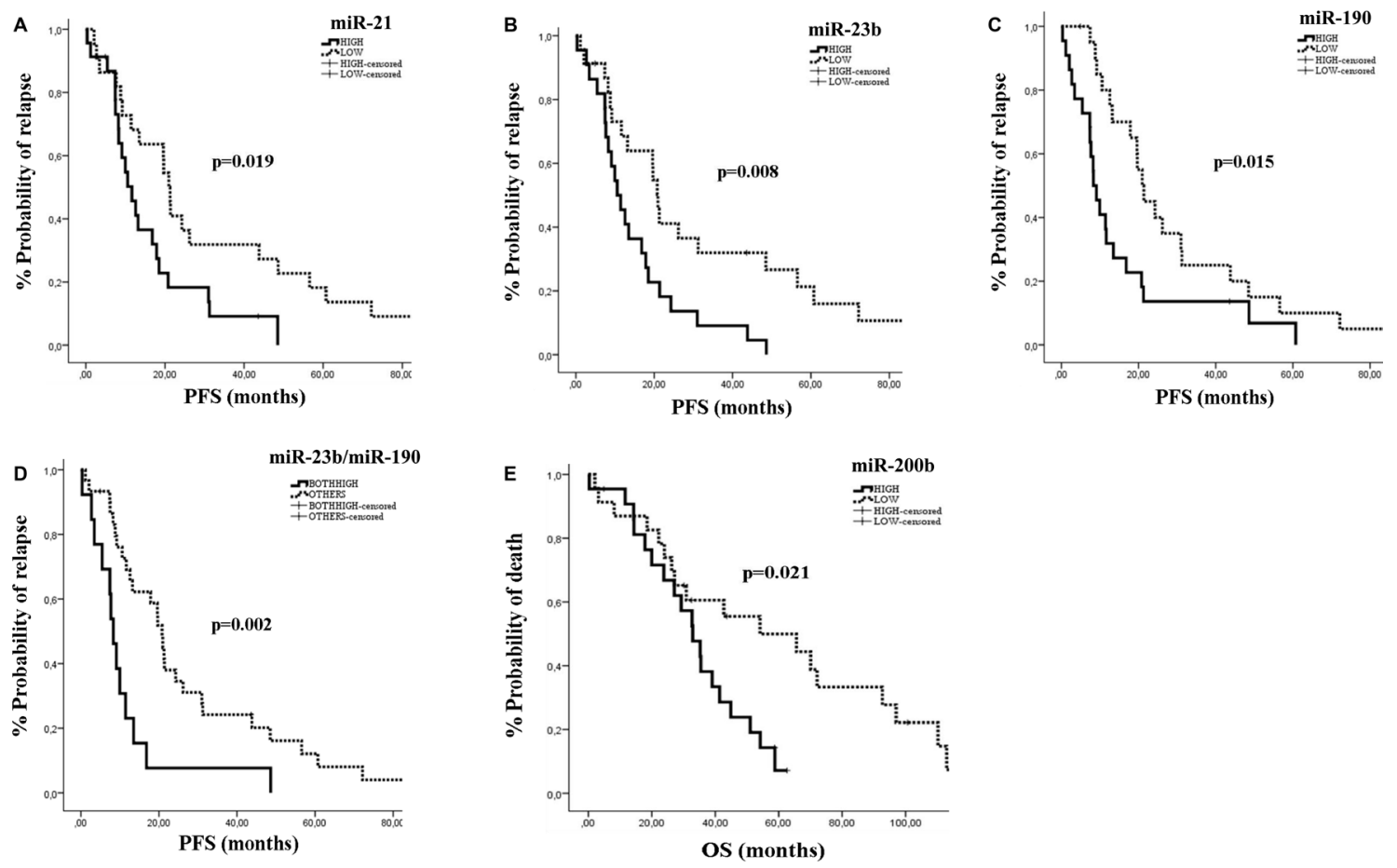

Figure 4: Kaplan-Meier analysis for PFS and OS according to the expression of circulating miRNAs in de novo metastatic patients. Progression free survival and overall survival in patients with high or low miR-21 (A), miR-23b (B), miR-190 (C), miR-23b/miR-190 (D) and miR-200b (E). Curves were compared using the log rank test. $P$ values are shown. 
Univariate analysis

Cox regression

PFS

HR $(95 \%$ CI)

Age (<63 vs $\geq 63$ )

Menopausal status (pre vs post)

PS (2-3 vs 0-1)

Disease status (recurrent vs de novo)

Grade (III vs I/II)

ER status (negative vs positive)

PR status (negative vs positive)

HER2 (positive vs negative)

Visceral metastases (no vs yes)

Non-visceral metastases (yes vs no)

Bone metastases (no vs yes)

miR-21 (high vs low)

miR-23b (high vs low)

miR-190 (high vs low)

miR-200b (high vs low)

miR-200c (high vs low)

miR-23b/190 (both high vs others)

Multivariate analysis

Menopausal status (pre vs post)

Disease status (recurrent vs de novo)

miR-200b (high vs low)

miR-23b/190 (both high vs others)
$1.337(0.806-2.218)$

$1.908(1.120-3.250)$

$1.788(0.943-3.393)$

$1.943(1.157-3.262)$

1.203 (0.701-2.065)

$1.600(0.879-2.911)$

1.151 (0.671-1.974)

$1.254(0.732-2.148)$

$1.002(0.568-1.766)$

1.268 (0.623-2.584)

1.321(0.798-2.187)

1.680 (1.009-2.799)

1.828 (1.101-3.035)

1.719 (1.038-2.846)

$1.396(0.834-2.336)$

1.229 (0.752-2.010)

2.107 (1.225-3.623)

$1.724(1.006-2.953)$

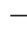

$-$

$2.054(1.195-3.530)$ $p$-value

0.261

$0.017^{*}$

0.075

$0.012^{*}$

0.503

0.124

0.609

0.410

0.996

0.513

0.278

$0.046^{*}$

$0.020^{*}$

$0.035^{*}$

0.204

0.411

$0.007^{*}$

$0.047^{*}$

$-$

$-$

$0.009^{*}$
OS

\begin{tabular}{|c|c|}
\hline $\mathrm{HR}(95 \% \mathrm{CI})$ & $p$-value \\
\hline $1.184(0.707-1.980)$ & 0,521 \\
\hline $1.628(0.964-2.923)$ & 0.067 \\
\hline $1.802(0.940-3.454)$ & 0.076 \\
\hline $2.231(1.306-3.814)$ & $0.003^{*}$ \\
\hline $1.232(0.703-2.159)$ & 0.465 \\
\hline $1.600(0.879-2.911)$ & 0.124 \\
\hline $1.151(0.671-1.974)$ & 0.609 \\
\hline $1.254(0.732-2.148)$ & 0.410 \\
\hline $1.002(0.568-1.766)$ & 0.996 \\
\hline $1.268(0.623-2.584)$ & 0.513 \\
\hline $1.083(0.634-1.849)$ & 0.771 \\
\hline $1.589(0.916-2.756)$ & 0.100 \\
\hline $1.299(0.772-2.186)$ & 0.324 \\
\hline $1.143(0.677-1.928)$ & 0.617 \\
\hline $1.893(1.076-3.331)$ & $0.027^{*}$ \\
\hline $1.096(0.658-1.025)$ & 0.725 \\
\hline $1.362(0.779-2.382)$ & 0.278 \\
\hline- & - \\
\hline $2.249(1.312-3.857)$ & $0.003^{*}$ \\
\hline $1.916(1.082-3.395)$ & $0.026^{*}$ \\
\hline
\end{tabular}

PFS, progression free survival; OS, overall survival; ER, estrogen receptor; PR, progesterone receptor; HER2, human epidermal growth factor receptor 2; CR, complete response; PR, partial response; SD, stable disease; PD, progressive disease; ${ }^{*} p<0.05$.

recurred and those who remained disease-free during follow-up [24]. Interestingly, herein we show that the same miRs, except for the dormancy-related miR-190, were also differentially expressed among patients with early and MBC. However, miR-190 was still included in the panel of the four miRs with the highest accuracy in predicting metastatic disease stage.

Differential miRNA expression in body fluids has been previously reported among early and MBC $[19,20,25]$ and suggests that miRNAs may be linked to a particular biology of breast carcinomas favoring metastatic progression. Our results suggest that similar gene regulatory networks underlie the complex interactions between tumor cells and cells of the tumor microenvironment [26] during both the subclinical and the clinically evident phase of the metastatic procedure. Moreover, they complement previous observations that these interactions can be uncovered in the circulation through the evaluation of unique miRNA profiles [27].

It has been consistently demonstrated that miRNA expression in tumor tissue is correlated with clinical and histopathological characteristics in breast cancer [28]. Here we demonstrate, for the first-time, higher plasma miR-21 and miR-200b expression in pre-menopausal compared to post-menopausal patients with metastatic disease. Although up-regulated miR-21 expression has been reported in ER-positive, in HER2-positive or in ERnegative breast cancer tissues [29, 30], in accordance to Jurkovicova et al. [25] we found no association between plasma miR-21 expression and hormone receptor or HER2 status. miR-200 family members are up-regulated by estradiol/estrogen signaling [31], whereas, miR-190 has been reported as the highest up-regulated miRNA in hormone-dependent breast cancers [32]. However in our 
cohort, no associations were revealed between miR-200 or miR-190 expression levels and hormone receptor status. On the other hand, we showed an association between low miR-190 and increased incidence of bone metastases. miR-190 is found among the miRNAs with multiple binding sites on gene targets known to be important for osteoclast differentiation and function, which is of vital importance for the development of bone metastases [33]. The herein reported association of low miR-190 levels with bone metastases suggests that miR-190 should be further investigated as a marker for organotropic metastasis in breast cancer. Moreover, our observation suggests that miRNAs involved in osteoclastogenesis may potentially serve as biomarkers for bone metastasis development.

The miR-200 family has conflicting roles in metastatic progression [34]. Interestingly, miRNAs of the miR-200 family are secreted in extracellular vesicles from metastatic mouse and human breast cancer cell lines to promote cancer cell metastasis [35]. In agreement with the pro-metastatic role of the miR-200 family, clinical studies demonstrate that miR-200b and miR-200c expression is increased in the plasma of metastatic patients and is correlated with poor outcomes [36-38]. We have previously shown that miR-200b and miR-200c expression was higher in relapsed compared to non-relapsed patients with early breast cancer [24] and herein we demonstrate that metastatic patients harbour higher levels of miR-200b and miR-200c compared to early breast cancer patients. In addition, miR-200b discriminated with high accuracy among patients with early and metastatic disease, whereas miR-200b high expression also emerged as independent predictor of poor survival both in the whole group as well as in the HER2-negative subgroup of metastatic patients.

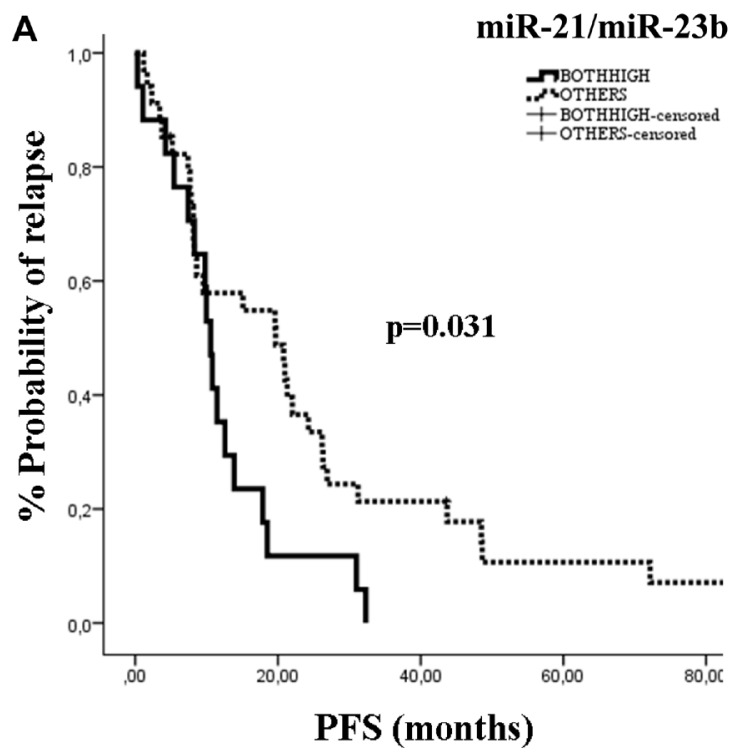

Although miR-23b was identified as a dormancyrelated miRNA in a bone marrow-metastatic human breast cancer cell line [39] and inhibited proliferation [40], cell migration and invasion in glioblastoma cells [41], in other studies miR-23b was correlated with metastasis and breast cancer progression. In clinical studies, miR-23b/27b/24 expression was higher in cancerous compared to normal tissues and was associated with poor outcome in breast cancer [42], thus supporting our observations regarding the association between high miR-23b and lower PFS in metastatic patients. Importantly, the combination of high miR-23b and miR-190 also emerged as an independent predictor for worse PFS. In contrast, we previously demonstrated that patients with early breast cancer who relapsed had lower miR-190 expression levels compared to non-relapsed patients [24] and accordingly, Yu et al., showed that patients with early disease and high miR190 expression in cancer tissue had a significantly better DFS and OS compared to those with low expression [43]. Our observations suggest a differential function of miR190 possibly related to the specific disease context. It has been suggested that various miRNAs could produce tumor suppressive or oncogenic effects as a result of the suppression of both tumor suppressive and oncogenic mRNAs and it is the balance between the multiple processes during carcinogenesis and tumor progression that ultimately determines the net function of a specific miRNA [11]. Patients with recurrent disease possibly represent a different prognostic group compared to those with de novo metastatic disease, although the issue remains controversial [44]. In our cohort, recurrent breast cancer was independently associated with decreased OS, both in the whole group as well as in the HER2-negative subgroup of metastatic patients. When we investigated

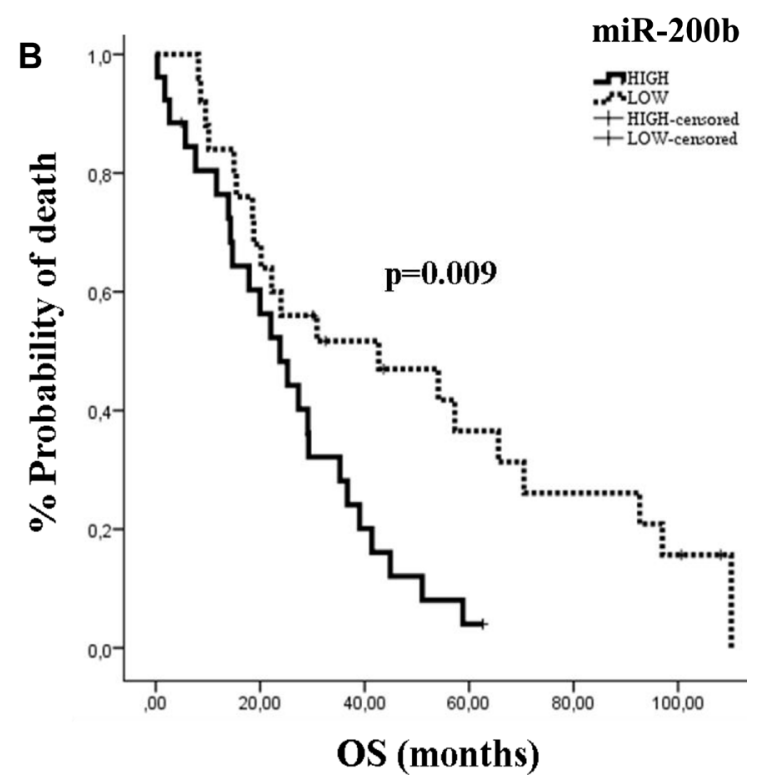

Figure 5: Kaplan-Meier analysis for PFS and OS according to the expression of circulating miRNAs in HER2-negative patients. Progression free survival according to the combined expression of miR-21/miR-23b (A) and overall survival according to the expression miR-200b (B). Curves were compared using the log rank test. $P$ values are shown. 
Table 5. Univariate and multivariate analysis for PFS and OS in de novo metastatic $(n=45)$ and $H E R 2-n e g a t i v e$ $(n=51)$ patients

\begin{tabular}{|c|c|c|c|c|}
\hline \multicolumn{5}{|c|}{ Univariate analysis } \\
\hline \multirow[t]{2}{*}{ Cox regression } & \multicolumn{2}{|l|}{ PFS } & \multicolumn{2}{|l|}{ OS } \\
\hline & HR $(95 \%$ CI $)$ & $p$-value & HR $(95 \%$ CI) & $p$-value \\
\hline \multicolumn{5}{|l|}{ de novo metastatic } \\
\hline Age $(<60$ vs $\geq 60)$ & $1.633(0.859-3.105)$ & 0.135 & $1.099(0.561-2.152)$ & 0.784 \\
\hline Menopausal status (pre vs post) & $2.420(1.181-4.957)$ & $0.016^{*}$ & $2.402(1.118-5.161)$ & $0.025^{*}$ \\
\hline PS (2-3 vs $0-1)$ & $2.364(1.167-4.789)$ & $0.017^{*}$ & $3.185(1.503-6.752)$ & 0.003 \\
\hline Grade (III vs I/II) & $1.047(0.509-2.154)$ & 0.901 & $1.112(0.524-2.357)$ & 0.782 \\
\hline ER status (negative vs positive) & $1.229(0.586-2.580)$ & 0.585 & $1.388(0.629-3.062)$ & 0.417 \\
\hline PR status (negative vs positive) & $1.223(0.646-2.315)$ & 0.536 & $1.215(0.609-2.425)$ & 0.581 \\
\hline HER2 (positive vs negative) & $1.465(0.778-2.758)$ & 0.237 & $1.049(0.528-2.084)$ & 0.891 \\
\hline Visceral metastases (yes vs no) & $1.138(0.549-2.361)$ & 0.728 & $1.480(0.704-3.112)$ & 0.301 \\
\hline Non-visceral metastases (yes vs no) & $1.668(0.511-5.439)$ & 0.396 & $1.846(0.552-6.174)$ & 0.320 \\
\hline Bone metastases (yes vs no) & $1.235(0.646-2.361)$ & 0.524 & $1.889(0.897-3.979)$ & 0.094 \\
\hline miR-21 (high vs low) & $2.257(1.164-4.376)$ & $0.016^{*}$ & $1.796(0.872-3.698)$ & 0.112 \\
\hline miR-23b (high vs low) & $2.200(1.150-4.211)$ & $0.017^{*}$ & $1.897(0.954-3.770)$ & 0.068 \\
\hline miR-190 (high vs low) & $2.023(1.078-3.794)$ & $0.028^{*}$ & $1.080(0.559-2.083)$ & 0.819 \\
\hline miR-200b (high vs low) & $1.767(0.911-3.428)$ & 0.092 & $2.359(1.111-5.007)$ & 0.025 \\
\hline miR-200c (high vs low) & $1.598(0.85602 .982)$ & 0.141 & $1.022(0.534-1.954)$ & 0.948 \\
\hline miR-23b/mir-190 (both high vs others) & $2.857(1.415-5.767)$ & $0.003^{*}$ & $1.477(0.729-2.992)$ & 0.279 \\
\hline \multicolumn{5}{|l|}{ Multvariate analysis } \\
\hline Menopausal status (pre vs post) & $4.125(1.871-9.091)$ & $<0.001^{*}$ & $5.658(2.485-12.879)$ & $<0.001^{*}$ \\
\hline PS (2-3 vs $0-1)$ & $3.773(1.754-8.130)$ & $0.001^{*}$ & & \\
\hline $\mathrm{miR}-23 \mathrm{~b} / \mathrm{miR}-190$ & $3.670(1.713-7.867)$ & $0.001^{*}$ & & \\
\hline \multicolumn{5}{|l|}{ HER2-negative } \\
\hline \multicolumn{5}{|l|}{ Univariate analysis } \\
\hline Age $(<63$ vs $\geq 63)$ & $1.280(0.700-2.341)$ & 0.423 & $1.145(0.625-2.098)$ & 0.661 \\
\hline Menopausal status (pre vs post) & $1.768(0.962-3.247)$ & 0.066 & $1.698(0.906-3.179)$ & 0.098 \\
\hline Performanc status (2-3 vs $0-1$ ) & $1.659(0.763-3.607)$ & 0.202 & $1.388(0.635-3.034)$ & 0.411 \\
\hline Disease status (recurrent vs de novo) & $2.059(1.132-3.747)$ & $0.018^{*}$ & $2.379(1.296-4.369)$ & $0.005^{*}$ \\
\hline Grade (III vs I/II) & $1.077(0.556-2.087)$ & 0.826 & $1.252(0.634-2.473)$ & 0.517 \\
\hline ER status (negative vs positive) & $1.593(0.701-3.622)$ & 0.266 & $1.102(0.462-2.631)$ & 0.826 \\
\hline PR status (negative vs positive) & $1.197(0.614-2.334)$ & 0.597 & $1.145(0.572-2.290)$ & 0.702 \\
\hline Visceral metastases (yes vs no) & $1.002(0.537-1.868)$ & 0.996 & $1.060(0.557-2.018)$ & 0.859 \\
\hline Non-visceral metastases (yes vs no) & $1.159(0.512-2.622)$ & 0.723 & $1.181(0.520-2.686)$ & 0.691 \\
\hline Bone metastases (yes vs no) & $1.632(0.900-2.958)$ & 0.107 & $1.511(0.815-2.800)$ & 0.190 \\
\hline miR-21 (high vs low) & $1.691(0.927-3.084)$ & 0.087 & $1.533(0.807-2.914)$ & 0.192 \\
\hline miR-23b (high vs low) & $1.715(0.952-3.088)$ & 0.072 & $1.336(0.734-2.432)$ & 0.343 \\
\hline miR-190 (high vs low) & $1.571(0.860-2.870)$ & 0.142 & $1.497(0.795-2.820)$ & 0.211 \\
\hline miR-200b (high vs low) & $1.346(0.739-2.450)$ & 0.331 & $2.342(1.214-4.518)$ & $0.011^{*}$ \\
\hline
\end{tabular}


miR-200c (high vs low)

miR-21/miR-23b (both high vs others)

\section{Multvariate analysis}

Disease status (recurrent vs de novo)

miR-200b (high vs low)
$1.169(0.654-2.091)$

$1.981(1.053-3.725)$

0.598

$1.333(0.728-2.440)$

0.352

$0.034^{*}$

1.962 (1.039-3.707)

$0.038^{*}$

PFS, progression free survival; OS, overall survival; ER, estrogen receptor; PR, progesterone receptor; HER2, human epidermal growth factor receptor 2; CR, complete response; PR, partial response; SD, stable disease; PD, progression disease; ${ }^{*} p<0.05$.

potential markers associated with outcome in patients with de novo metastatic disease, we found that premenopausal status and performance status independently predicted for worse PFS, whereas, the miR-23b/miR-190 high also emerged as an independent predictor for worse PFS.

MiR-21 has been extensively studied as an oncogenic miRNA that promotes cell growth, invasion and tumor metastasis through the inhibition of tumor suppressor genes [45]. Clinical evidence indicates that miR-21 is upregulated in breast cancer tissue and is correlated with advanced stages of disease, metastasis and poor prognosis in breast cancer [46, 47]. Furthermore, several reports demonstrate the potential of circulating miR-2 1 as a marker for the detection of breast cancer $[48,49]$. In our previous report, miR-21 expression levels could discriminate among relapsed and non-relapsed patients with early breast cancer [24] and herein, miR-21 expression distinguished with high accuracy patients with early from patients with metastatic disease. These and other observations suggest that circulating miR-21 could also have a role as a marker for the diagnosis of metastasis in breast cancer [50]. Interestingly, although high miR-21 expression was associated with lower PFS in the whole group and in de novo metastatic patients, it does not add further diagnostic value regarding the aggressiveness of metastatic disease in these patients, since miR-21 expression was correlated with pre-menopausal status that independently predicted for shorter PFS.

It is increasingly recognized that dynamic changes in miRNA expression profiles are generated during tumor initiation and metastatic progression and many studies have focused on analyzing circulating miRNAs to determine their potential as biomarkers [51]. However, different biological and technical factors can influence the expression profiles of circulating miRNAs [52] and in the present study, we considered pre-analytical and analytical parameters very carefully, taking into account the variables that could lead to bias in miRNA quantification [53, 54].

Currently, only a few studies have identified circulating miRNAs associated with prognosis in patients with $\mathrm{MBC}$ and although our results are promising, some limitations exist and should be addressed in future studies. Due to the relatively small sample size, our results should be further validated in a larger study to allow for more robust statistical associations. The higher number of study patients would allow for firm conclusions to be drawn regarding patient subgroups for which different miRNAs represent potential prognostic biomarkers. There is as yet no conclusive evidence on the clinical utility of miRNAs, however, the data presented in this manuscript, as well as in other reports, suggest that circulating miRNAs represent non-invasive biomarkers to be used not only in the detection of breast cancer, but also in the prediction of metastasis and disease outcome.

In summary, the results of this study demonstrate that a panel of four miRNAs, namely, miR-21, miR-190, miR-200b and miR-200c can discriminate between early and MBC. Moreover, it is shown that miRNA expression can independently predict for patient outcome in MBC. Our findings support the concept that circulating miRNAs represent non-invasive biomarkers with significant diagnostic and prognostic implications in breast cancer. Further studies in large homogenous populations using standardized techniques are required to establish the value of these markers.

\section{MATERIALS AND METHODS}

\section{Patients}

In the present study we included patients with early $(n=133)$ and metastatic $(n=110)$ breast cancer (Figure 6). The cohort of patients with early disease has been described in our previous work [24]. Patients with MBC were treated at the Department of Medical Oncology of the University Hospital of Heraklion (Crete, Greece) from 2003 - 2010. Peripheral blood samples were obtained before the initiation of first-line chemotherapy. Samples were also collected from 23 normal blood donors to serve as controls for miRNA evaluation. All patients and normal donors had signed an informed consent to participate in the study which was approved by the Ethics and Scientific Committee of the University Hospital of Heraklion, Greece.

Clinical characteristics and follow-up information for each patient were prospectively collected. Peripheral blood from healthy donors and patients was drawn early in the morning and was collected in EDTA- tubes. Plasma was subsequently isolated within 2 hours by centrifugation in $2500 \mathrm{rpm}$ for 15 minutes at $4^{\circ} \mathrm{C}$, followed by a second 
centrifugation in $2000 \mathrm{~g}$ for 15 minutes at $4^{\circ} \mathrm{C}$, to remove cellular debris. Samples were kept in aliquots at $-80^{\circ} \mathrm{C}$ until further use.

\section{RNA isolation}

Total RNA was extracted from plasma using Trizol LS (Ambion, Life Technologies), as previously described [24]. Briefly, plasma was thawed on ice, centrifuged to remove cellular debris and 25 fmoles of the synthetic $C$. elegans miRNA cel-miR-39 (Qiagen Inc.-USA) was added after denaturation to each sample as an exogenous control. Aqueous phase was separated by adding chloroform followed by incubation on ice for 10 minutes. After centrifugation, equal volume of $700 \mu \mathrm{l}$ of supernatant, from each sample containing the RNA was precipitated by adding 0.7 volumes of isopropanol and $1 \mu \mathrm{l}$ of glycogen. RNA pellet was resuspended in $50 \mu \mathrm{l}$ RNAse-free water. RNA from all samples was kept at $-80^{\circ} \mathrm{C}$ until further use in the subsequent real-time qPCR.

Plasma samples presenting a change of colour to pink $(n=25)$, suggesting the presence of hemolysis and samples from patients lost to follow-up $(n=8)$, were not processed for RNA isolation (Figure 6).

\section{Quantitative real-time PCR analysis and miRNA expression}

Reverse transcription and RT-qPCR was performed according to manufacturer's instructions and as previously described [24]. In brief, total RNA input of $1.67 \mu \mathrm{l}$ was reverse transcribed using the TaqMan miRNA Reverse Transcription kit and miRNA specific stem-loop primers (Applied Biosystmes, Foster City, CA, USA) in a $5 \mu \mathrm{l}-$ reaction. cDNA was diluted at $30 \mu \mathrm{l}$ and each miRNA was assessed by RT-qPCR. The quantitative real- time PCR reaction was carried out on a ViiA 7 Real- Time PCR System (Applied Biosystems, Foster City, CA, USA). All the assays were performed in triplicates. Appropriate negative controls were used in both cDNA synthesis and RT-qPCR reactions where RNA input was replaced by $\mathrm{H}_{2} \mathrm{O}$ and no template control was used, respectively. The average expression level for each miRNA was calculated by the $2^{-\Delta \mathrm{Ct}}$ method relative to the average of miR-23a which was used as a reference gene. We choose miR-23a as an endogenous control since it was stably and reproducibly expressed among early and MBC patients and among patients and normal donors (Mann-Whitney test, $p>0.05$ ). The fold change of target miRNAs relative to miRNA expressed in

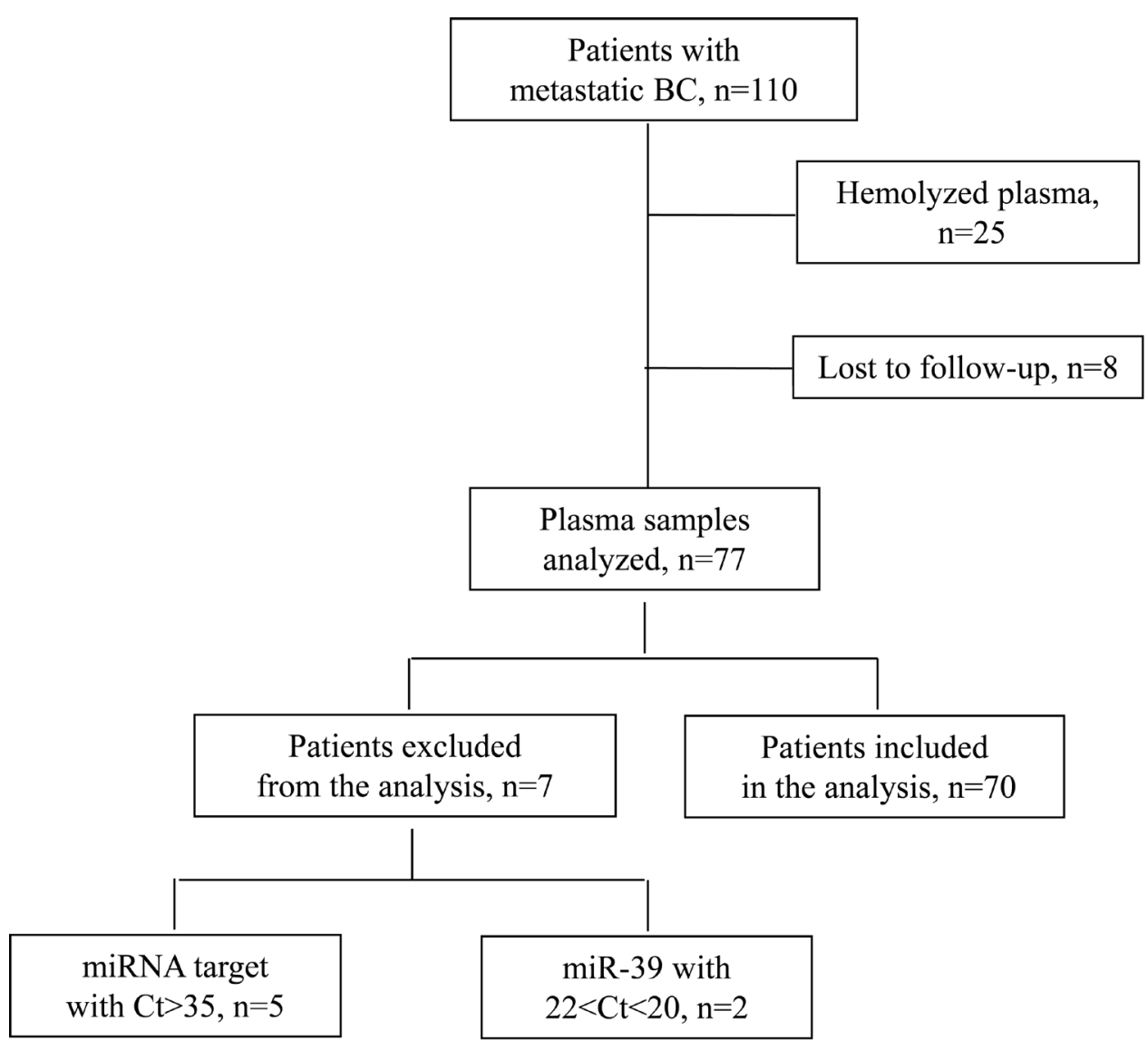

Figure 6: Flow chart of the study; Ct: cycle threshold. 
normal controls was calculated by the $2^{-\Delta \Delta \mathrm{Ct}}$ method [55]. Samples with mean $\mathrm{Ct}>35$ for target miRNAs $(n=5$; Figure 6) as well as samples with mean $\mathrm{Ct}>22$ or $\mathrm{Ct}<20$ of cel-miR-39, suggestive of inefficient RNA extraction, were excluded from the analysis ( $n=2$; Figure 6$)$. miR451 and miR-23a expression levels were assessed to test for haemolysis in plasma samples, as previously described [56]. A total of 70 plasma samples were processed for further miRNA assessment ( $n=70$; Figure 6).

\section{Statistical analysis}

The statistical analysis was performed using the SPSS software package, version 22.0 (SPSS Inc. Chicago IL). Patients were divided into high and low expression according to the median value for each miRNA expression. Patients with miRNA expression above or equal to the median values were characterized as having high, whereas those with miRNA expression below the median as having low expression. The median cut-off values were preserved in the whole group and across subgroup analysis. Correlations of expression between the different miRNAs were performed by Spearmans' test. The chisquared test was used to estimate associations between miRNA expression and clinicopathological characteristics. Mann-Whitney test was used to examine the differential expression between metastatic and early breast cancer patients. The associations between circulating miRNA expression levels and PFS or OS were assessed by Kaplan Meier method, log rank test (Mantel-Cox) and Cox proportional hazard regression models. PFS and OS were calculated from the start of treatment until the date of the first documented disease progression or death and last follow-up, respectively. To evaluate the value of circulating miRNAs in distinguishing between early and metastatic breast cancer, receiver operating characteristics (ROC) curves were constructed and areas under the curves (AUC) were calculated. The Youden index (sensitivity + specificity - 1) was used to set the optimal cut-off point. Statistical significance was set at $p<0.05$ (two-sided test). This report is written according to the reporting recommendations for tumor marker prognostic studies (REMARK criteria) [57].

\section{Author contributions}

CP coordinated the work, performed control experiments and molecular analysis, analyzed the data, interpreted the results and drafted the manuscript. GS, $\mathrm{MN}$ and MS collected the clinicopathological data of the patients, participated in data acquisition and interpretation. LT, AM, MP, and GM participated in laboratory work. DM was involved in study design, data interpretation, participated in the preparation of the manuscript and provided general support. SA designed, coordinated and supervised the study, was involved in data analysis and interpretation and drafted the manuscript.

\section{ACKNOWLEDGMENTS}

We are grateful to all patients and volunteers who participated in this study.

\section{FUNDING}

This work was partly supported by the Hellenic Society of Medical Oncology (HESMO). Also, this work was partly supported by the Anticancer Research Support Association (ARSA). The funding organizations had no role in study design, data collection and analysis, decision to publish and preparation of the manuscript.

\section{CONFLICTS OF INTEREST}

The authors declare no conflicts of interests.

\section{REFERENCES}

1. Siegel RL, Miller KD, Jemal A. Cancer statistics, 2018. CA Cancer J Clin. 2018; 68:7-30. https://doi.org/10.3322/ caac. 21442.

2. Redig AJ, McAllister SS. Breast cancer as a systemic disease: a view of metastasis. J Intern Med. 2013; 274:11326. https://doi.org/10.1111/joim.12084.

3. Lim B, Hortobagyi GN. Current challenges of metastatic breast cancer. Cancer Metastasis Rev. 2016; 35:495-514. https://doi.org/10.1007/s10555-016-9636-y.

4. Cardoso F, Senkus E, Costa A, Papadopoulos E, Aapro M, Andre F, Harbeck N, Aguilar Lopez B, Barrios CH, Bergh J, Biganzoli L, Boers-Doets CB, Cardoso MJ, et al. 4th ESOESMO International Consensus Guidelines for Advanced Breast Cancer (ABC 4)dagger. Ann Oncol. 2018; 29:163457. https://doi.org/10.1093/annonc/mdy192.

5. Yamamoto N, Watanabe $\mathrm{T}$, Katsumata N, Omuro Y, Ando M, Fukuda H, Takue Y, Narabayashi M, Adachi I, Takashima S. Construction and validation of a practical prognostic index for patients with metastatic breast cancer. J Clin Oncol. 1998; 16:2401-8. https://doi.org/10.1200/ JCO.1998.16.7.2401.

6. Largillier R, Ferrero JM, Doyen J, Barriere J, Namer M, Mari V, Courdi A, Hannoun-Levi JM, Ettore F, BirtwislePeyrottes I, Balu-Maestro C, Marcy PY, Raoust I, et al. Prognostic factors in 1,038 women with metastatic breast cancer. Ann Oncol. 2008; 19:2012-9. https://doi. org/10.1093/annonc/mdn424.

7. Turashvili G, Brogi E. Tumor Heterogeneity in Breast Cancer. Front Med (Lausanne). 2017; 4:227. https://doi. org/10.3389/fmed.2017.00227.

8. Martelotto LG, Ng CK, Piscuoglio S, Weigelt B, Reis-Filho JS. Breast cancer intra-tumor heterogeneity. Breast Cancer Res. 2014; 16:210. https://doi.org/10.1186/bcr3658.

9. Bartel DP. MicroRNAs: target recognition and regulatory functions. Cell. 2009; 136:215-33. https://doi.org/10.1016/j. cell.2009.01.002. 
10. Iorio MV, Croce CM. MicroRNA dysregulation in cancer: diagnostics, monitoring and therapeutics. A comprehensive review. EMBO Mol Med. 2017; 9:852. https://doi. org/10.15252/emmm.201707779.

11. Svoronos AA, Engelman DM, Slack FJ. OncomiR or Tumor Suppressor? The Duplicity of MicroRNAs in Cancer. Cancer Res. 2016; 76:3666-70. https://doi. org/10.1158/0008-5472.CAN-16-0359.

12. Peng Y, Croce CM. The role of MicroRNAs in human cancer. Signal Transduct Target Ther. 2016; 1:15004. https://doi.org/10.1038/sigtrans.2015.4.

13. Skourti E, Logotheti S, Kontos CK, Pavlopoulou A, Dimoragka PT, Trougakos IP, Gorgoulis V, Scorilas A, Michalopoulos I, Zoumpourlis V. Progression of mouse skin carcinogenesis is associated with the orchestrated deregulation of mir-200 family members, mir-205 and their common targets. Mol Carcinog. 2016; 55:1229-42. https:// doi.org/10.1002/mc.22365.

14. Hayes J, Peruzzi PP, Lawler S. MicroRNAs in cancer: biomarkers, functions and therapy. Trends Mol Med. 2014; 20:460-9. https://doi.org/10.1016/j.molmed.2014.06.005.

15. Zhang JX, Song W, Chen ZH, Wei JH, Liao YJ, Lei J, Hu M, Chen GZ, Liao B, Lu J, Zhao HW, Chen W, He YL, et al. Prognostic and predictive value of a microRNA signature in stage II colon cancer: a microRNA expression analysis. Lancet Oncol. 2013; 14:1295-306. https://doi.org/10.1016/ S1470-2045(13)70491-1.

16. Ueda T, Volinia S, Okumura H, Shimizu M, Taccioli C, Rossi S, Alder H, Liu CG, Oue N, Yasui W, Yoshida K, Sasaki H, Nomura S, et al. Relation between microRNA expression and progression and prognosis of gastric cancer: a microRNA expression analysis. Lancet Oncol. 2010; 11:136-46. https://doi.org/10.1016/ S1470-2045(09)70343-2.

17. Toiyama Y, Takahashi M, Hur K, Nagasaka T, Tanaka K, Inoue Y, Kusunoki M, Boland CR, Goel A. Serum miR21 as a diagnostic and prognostic biomarker in colorectal cancer. J Natl Cancer Inst. 2013; 105:849-59. https://doi. org/10.1093/jnci/djt101.

18. Lin XJ, Chong Y, Guo ZW, Xie C, Yang XJ, Zhang Q, Li SP, Xiong Y, Yuan Y, Min J, Jia WH, Jie Y, Chen MS, et al. A serum microRNA classifier for early detection of hepatocellular carcinoma: a multicentre, retrospective, longitudinal biomarker identification study with a nested case-control study. Lancet Oncol. 2015; 16:804-15. https:// doi.org/10.1016/S1470-2045(15)00048-0.

19. Roth C, Rack B, Muller V, Janni W, Pantel K, Schwarzenbach H. Circulating microRNAs as blood-based markers for patients with primary and metastatic breast cancer. Breast Cancer Res. 2010; 12:R90. https://doi. org/10.1186/bcr2766.

20. Eichelser C, Flesch-Janys D, Chang-Claude J, Pantel K, Schwarzenbach H. Deregulated serum concentrations of circulating cell-free microRNAs miR-17, miR-34a, miR155 , and miR-373 in human breast cancer development and progression. Clin Chem. 2013; 59:1489-96. https://doi. org/10.1373/clinchem.2013.205161.

21. Hu Z, Chen X, Zhao Y, Tian T, Jin G, Shu Y, Chen Y, Xu L, Zen K, Zhang C, Shen H. Serum microRNA signatures identified in a genome-wide serum microRNA expression profiling predict survival of non-small-cell lung cancer. J Clin Oncol. 2010; 28:1721-6. https://doi.org/10.1200/ JCO.2009.24.9342.

22. Wu X, Somlo G, Yu Y, Palomares MR, Li AX, Zhou W, Chow A, Yen Y, Rossi JJ, Gao H, Wang J, Yuan YC, Frankel $\mathrm{P}$, et al. De novo sequencing of circulating miRNAs identifies novel markers predicting clinical outcome of locally advanced breast cancer. J Transl Med. 2012; 10:42. https://doi.org/10.1186/1479-5876-10-42.

23. Li H, Liu J, Chen J, Wang H, Yang L, Chen F, Fan S, Wang J, Shao B, Yin D, Zeng M, Li M, Li J, et al. A serum microRNA signature predicts trastuzumab benefit in HER2positive metastatic breast cancer patients. Nat Commun. 2018; 9:1614. https://doi.org/10.1038/s41467-018-03537-w.

24. Papadaki C, Stratigos M, Markakis G, Spiliotaki M, Mastrostamatis G, Nikolaou C, Mavroudis D, Agelaki S. Circulating microRNAs in the early prediction of disease recurrence in primary breast cancer. Breast Cancer Res. 2018; 20:72. https://doi.org/10.1186/s13058-018-1001-3.

25. Jurkovicova D, Smolkova B, Magyerkova M, Sestakova Z, Kajabova VH, Kulcsar L, Zmetakova I, Kalinkova L, Krivulcik T, Karaba M, Benca J, Sedlackova T, Minarik G, et al. Down-regulation of traditional oncomiRs in plasma of breast cancer patients. Oncotarget. 2017; 8:77369-84. https://doi.org/10.18632/oncotarget.20484.

26. Ungefroren H, Sebens S, Seidl D, Lehnert H, Hass R. Interaction of tumor cells with the microenvironment. Cell Commun Signal. 2011; 9:18. https://doi. org/10.1186/1478-811X-9-18.

27. Gennarino VA, D'Angelo G, Dharmalingam G, Fernandez S, Russolillo G, Sanges R, Mutarelli M, Belcastro V, Ballabio A, Verde P, Sardiello M, Banfi S. Identification of microRNA-regulated gene networks by expression analysis of target genes. Genome Res. 2012; 22:1163-72. https://doi. org/10.1101/gr.130435.111.

28. Kurozumi S, Yamaguchi Y, Kurosumi M, Ohira M, Matsumoto H, Horiguchi J. Recent trends in microRNA research into breast cancer with particular focus on the associations between microRNAs and intrinsic subtypes. J Hum Genet. 2017; 62:15-24. https://doi.org/10.1038/ jhg.2016.89.

29. Blenkiron C, Goldstein LD, Thorne NP, Spiteri I, Chin SF, Dunning MJ, Barbosa-Morais NL, Teschendorff AE, Green AR, Ellis IO, Tavare S, Caldas C, Miska EA. MicroRNA expression profiling of human breast cancer identifies new markers of tumor subtype. Genome Biol. 2007; 8:R214. https://doi.org/10.1186/gb-2007-8-10-r214.

30. Petrovic N, Mandusic V, Dimitrijevic B, Roganovic J, Lukic $\mathrm{S}$, Todorovic L, Stanojevic B. Higher miR-21 expression in invasive breast carcinomas is associated with positive 
estrogen and progesterone receptor status in patients from Serbia. Med Oncol. 2014; 31:977. https://doi.org/10.1007/ s12032-014-0977-5.

31. Bhat-Nakshatri P, Wang G, Collins NR, Thomson MJ, Geistlinger TR, Carroll JS, Brown M, Hammond S, Srour EF, Liu Y, Nakshatri H. Estradiol-regulated microRNAs control estradiol response in breast cancer cells. Nucleic Acids Res. 2009; 37:4850-61. https://doi.org/10.1093/nar/ gkp500.

32. Cizeron-Clairac G, Lallemand F, Vacher S, Lidereau R, Bieche I, Callens C. MiR-190b, the highest up-regulated miRNA in ERalpha-positive compared to ERalphanegative breast tumors, a new biomarker in breast cancers? BMC Cancer. 2015; 15:499. https://doi.org/10.1186/ s12885-015-1505-5.

33. Ell B, Mercatali L, Ibrahim T, Campbell N, Schwarzenbach H, Pantel K, Amadori D, Kang Y. Tumor-induced osteoclast miRNA changes as regulators and biomarkers of osteolytic bone metastasis. Cancer Cell. 2013; 24:542-56. https://doi. org/10.1016/j.ccr.2013.09.008.

34. Korpal M, Kang Y. The emerging role of miR-200 family of microRNAs in epithelial-mesenchymal transition and cancer metastasis. RNA Biol. 2008; 5:115-9.

35. Le MT, Hamar P, Guo C, Basar E, Perdigao-Henriques R, Balaj L, Lieberman J. miR-200-containing extracellular vesicles promote breast cancer cell metastasis. J Clin Invest. 2014; 124:5109-28. https://doi.org/10.1172/JCI75695.

36. Madhavan D, Zucknick M, Wallwiener M, Cuk K, Modugno C, Scharpff M, Schott S, Heil J, Turchinovich A, Yang R, Benner A, Riethdorf S, Trumpp A, et al. Circulating miRNAs as surrogate markers for circulating tumor cells and prognostic markers in metastatic breast cancer. Clin Cancer Res. 2012; 18:5972-82. https://doi. org/10.1158/1078-0432.CCR-12-1407.

37. Madhavan D, Peng C, Wallwiener M, Zucknick M, Nees J, Schott S, Rudolph A, Riethdorf S, Trumpp A, Pantel K, Sohn C, Chang-Claude J, Schneeweiss A, et al. Circulating miRNAs with prognostic value in metastatic breast cancer and for early detection of metastasis. Carcinogenesis. 2016; 37:461-70. https://doi.org/10.1093/carcin/bgw008.

38. Antolin S, Calvo L, Blanco-Calvo M, Santiago MP, Lorenzo-Patino MJ, Haz-Conde M, Santamarina I, Figueroa A, Anton-Aparicio LM, Valladares-Ayerbes M. Circulating miR-200c and miR-141 and outcomes in patients with breast cancer. BMC Cancer. 2015; 15:297. https://doi. org/10.1186/s12885-015-1238-5.

39. Ono M, Kosaka N, Tominaga N, Yoshioka Y, Takeshita F, Takahashi RU, Yoshida M, Tsuda H, Tamura K, Ochiya T. Exosomes from bone marrow mesenchymal stem cells contain a microRNA that promotes dormancy in metastatic breast cancer cells. Sci Signal. 2014; 7:ra63. https://doi. org/10.1126/scisignal.2005231.

40. Geng J, Luo H, Pu Y, Zhou Z, Wu X, Xu W, Yang Z. Methylation mediated silencing of miR-23b expression and its role in glioma stem cells. Neurosci Lett. 2012; 528:1859. https://doi.org/10.1016/j.neulet.2012.08.055.

41. Loftus JC, Ross JT, Paquette KM, Paulino VM, Nasser S, Yang Z, Kloss J, Kim S, Berens ME, Tran NL. miRNA expression profiling in migrating glioblastoma cells: regulation of cell migration and invasion by miR-23b via targeting of Pyk2. PLoS One. 2012; 7:e39818. https://doi. org/10.1371/journal.pone.0039818.

42. Jin L, Wessely O, Marcusson EG, Ivan C, Calin GA, Alahari SK. Prooncogenic factors miR-23b and miR$27 \mathrm{~b}$ are regulated by Her2/Neu, EGF, and TNF-alpha in breast cancer. Cancer Res. 2013; 73:2884-96. https://doi. org/10.1158/0008-5472.CAN-12-2162.

43. Yu Y, Luo W, Yang ZJ, Chi JR, Li YR, Ding Y, Ge J, Wang X, Cao XC. miR-190 suppresses breast cancer metastasis by regulation of TGF-beta-induced epithelial-mesenchymal transition. Mol Cancer. 2018; 17:70. https://doi.org/10.1186/ s12943-018-0818-9.

44. Dawood S, Broglio K, Ensor J, Hortobagyi GN, Giordano $\mathrm{SH}$. Survival differences among women with de novo stage IV and relapsed breast cancer. Ann Oncol. 2010; 21:216974. https://doi.org/10.1093/annonc/mdq220.

45. Aleckovic M, Kang Y. Regulation of cancer metastasis by cell-free miRNAs. Biochim Biophys Acta. 2015; 1855:2442. https://doi.org/10.1016/j.bbcan.2014.10.005.

46. Iorio MV, Ferracin M, Liu CG, Veronese A, Spizzo R, Sabbioni S, Magri E, Pedriali M, Fabbri M, Campiglio M, Menard S, Palazzo JP, Rosenberg A, et al. MicroRNA gene expression deregulation in human breast cancer. Cancer Res. 2005; 65:7065-70. https://doi.org/10.1158/0008-5472. CAN-05-1783.

47. Yan LX, Huang XF, Shao Q, Huang MY, Deng L, Wu QL, Zeng YX, Shao JY. MicroRNA miR-21 overexpression in human breast cancer is associated with advanced clinical stage, lymph node metastasis and patient poor prognosis. RNA. 2008; 14:2348-60. https://doi.org/10.1261/ rna.1034808.

48. Matamala N, Vargas MT, Gonzalez-Campora R, Minambres R, Arias JI, Menendez P, Andres-Leon E, Gomez-Lopez G, Yanowsky K, Calvete-Candenas J, Inglada-Perez L, Martinez-Delgado B, Benitez J. Tumor microRNA expression profiling identifies circulating microRNAs for early breast cancer detection. Clin Chem. 2015; 61:1098106. https://doi.org/10.1373/clinchem.2015.238691.

49. Wang F, Zheng Z, Guo J, Ding X. Correlation and quantitation of microRNA aberrant expression in tissues and sera from patients with breast tumor. Gynecol Oncol. 2010; 119:586-93. https://doi.org/10.1016/j. ygyno.2010.07.021.

50. Asaga S, Kuo C, Nguyen T, Terpenning M, Giuliano AE, Hoon DS. Direct serum assay for microRNA-21 concentrations in early and advanced breast cancer. Clin Chem. 2011; 57:84-91. https://doi.org/10.1373/ clinchem.2010.151845. 
51. Schwarzenbach H, Nishida N, Calin GA, Pantel K. Clinical relevance of circulating cell-free microRNAs in cancer. Nat Rev Clin Oncol. 2014; 11:145-56. https://doi.org/10.1038/ nrclinonc.2014.5.

52. Umu SU, Langseth H, Bucher-Johannessen C, Fromm B, Keller A, Meese E, Lauritzen M, Leithaug M, Lyle R, Rounge TB. A comprehensive profile of circulating RNAs in human serum. RNA Biol. 2018; 15:242-50. https://doi. org/10.1080/15476286.2017.1403003.

53. McDonald JS, Milosevic D, Reddi HV, Grebe SK, Algeciras-Schimnich A. Analysis of circulating microRNA: preanalytical and analytical challenges. Clin Chem. 2011; 57:833-40. https://doi.org/10.1373/clinchem.2010.157198.

54. Becker N, Lockwood CM. Pre-analytical variables in miRNA analysis. Clin Biochem. 2013; 46:861-8. https:// doi.org/10.1016/j.clinbiochem.2013.02.015.
55. Schmittgen TD, Livak KJ. Analyzing real-time PCR data by the comparative C(T) method. Nat Protoc. 2008; 3:1101-8.

56. Blondal T, Jensby Nielsen S, Baker A, Andreasen D, Mouritzen P, Wrang Teilum M, Dahlsveen IK. Assessing sample and miRNA profile quality in serum and plasma or other biofluids. Methods. 2013; 59:S1-6. https://doi. org/10.1016/j.ymeth.2012.09.015.

57. McShane LM, Altman DG, Sauerbrei W, Taube SE, Gion M, Clark GM, and Statistics Subcommittee of the NCIEORTC Working Group on Cancer Diagnostics. Reporting recommendations for tumour MARKer prognostic studies (REMARK). Br J Cancer. 2005; 93:387-91. https://doi. org/10.1038/sj.bjc.6602678. 